\title{
THE INFLUENCE OF ATTENTION TO LANGUAGE FORM ON THE PRODUCTION OF WEAK FORMS BY POLISH LEARNERS OF ENGLISH
}

\author{
AGATA BARAŃSKA \\ University of Łódź \\ b.agata@onet.eu \\ MAGDALENA ZAJAC \\ University of Łódź \\ zajac1234@gmail.com
}

\begin{abstract}
The paper discusses a study whose aim was to examine the impact of attention to language form and task type on the realisation of English function words by Polish learners of English. An additional goal was to investigate whether style-induced pronunciation shifts may depend on the degree of foreign accent. A large part of the paper concentrates on the issue of defining 'weakness' in English weak forms and considers priorities in English pronunciation teaching as far as the realisation of function words is concerned. The participants in the study were 12 advanced Polish learners of English, who were divided into two groups: 6 who were judged to speak with a slight degree of foreign accent and 6 who were judged to speak with a high degree of foreign accent. The subjects' pronunciation was analysed in three situations in which we assume their attention was increasingly paid to speech form (spontaneous speech, prepared speech, reading). The results of the study suggest that increased attention to language form caused the participants to realise more function words as unstressed, although the effect was small. It was also found that one of the characteristics of English weak forms, the lack of stress, was realised correctly by the participants in the majority of cases. Finally, the results of the study imply that, in the case under investigation, the effect of attention to language form is weakly or not at all related to the degree of foreign accent.
\end{abstract}

\section{Attention to language form in L2 pronunciation}

Tarone $(1979 ; 1982)$ hypothesised that a learner's interlanguage is a continuum of styles, which range from the superordinate on one end and the vernacular on the other. Following Labov's (1969) work, Tarone argues that the superordinate is the style that is used in formal situations, when the learner pays the greatest amount of attention to language form. The vernacular style, on the other hand, is used in informal situations, when the learner pays least attention to language form. The crucial difference between the two styles is that the interlanguage superordinate is most permeable to invasion from the rule system of the target language (TL). It follows from this assumption that more 
formal elicitation tasks such as word-list reading (in which, presumably, the learner's attention is maximally focused on language form) will induce the L2 speaker to use more TL forms than less formal tasks such as free speech (in which we might assume the learner is less focused on the language form). Support for Tarone's (1979; 1982) claims can be found in a study by Dickerson and Dickerson (1977), who examined the pronunciation of Japanese learners of English. The variable under investigation was the participants' production of $/ \mathrm{r} /$ in the context of a preceding consonant and a following high vowel. It was found that the subjects produced /r/ almost $100 \%$ correctly in a wordlist reading task but only $50 \%$ correctly in free speech. Similar results were obtained by Gatbonton (1975), who investigated the English pronunciation of French Canadians. Schmidt (1987) examined the influence L1 transfer and style on the production of English dental fricatives by native speakers of Egyptian Arabic. The results revealed that the frequency of the produced TL forms increased when moving from a reading passage to word-list reading and minimal-pair reading. Since it could be assumed that the participants were maximally focused on the investigated pronunciation feature when asked to read the minimal pairs, the findings of Schmidt lend further support for Tarone's $(1979 ; 1982)$ hypothesis. Beebe (1980) examined the realisation of initial and final $/ \mathrm{r} /$ by Thai learners of English and also found that the distribution of the investigated pronunciation feature shifted according to task type. However, her results show that the relationship between style/attention to speech and the production of TL forms may be more complex than as suggested by the findings of Dickerson and Dickerson (1977), Gatbonton (1975) and Schmidt (1987). More specifically, she observed that, in the case of final /r/s, the participants supplied more TL forms in a word-list reading task than in a conversation task. In the case of initial /r/s, an opposite pattern was observed. As regards initial $/ \mathrm{r} / \mathrm{s}$, it was also found that the participants used more prestige native language forms in the word-list reading task than in free speech, which suggests that the superordinate style is permeable to invasion not only from the target language but also from the native language.

The results of several other studies that investigate stylistic changes in L2 pronunciation run counter to Tarone's $(1979 ; 1982)$ claim that a formal context prompts learners to use more TL forms. For instance, Weinberger (1987) studied epenthesis and deletion in the English pronunciation of Mandarin Chinese speakers and found no significant change in the overall frequency of final cluster simplifications across different elicitation tasks (word-list reading, paragraph reading and storytelling). It also transpired that epenthesis was used more frequently in word-list reading, which was taken to mean that it is the linguistic context provided by the elicitation task rather than task formality that motivates shifts in the use of different simplification patterns. Lin (2001) also explored stylistic variations in Chinese learner's pronunciation of English consonant clusters. The obtained results accorded with Weinberger's findings in that increased accuracy was not significantly correlated with increased task formality. Zampini (1994) focused on the acquisition of the spirantized allophones of Spanish voiced stops by native speakers of English. The participants were required to answer a series of questions (the informal task) and read a text passage (the formal task). The results of the study showed that more TL forms were produced during the conversation task than during the reading task. Zampini explains that the participants might have used more spirantised variants in the informal task, because spirantization of $/ \mathrm{b} /$ and $/ \mathrm{g} /$ is also 
possible in casual native English pronunciation. The finding that the participants exhibited more stop realisations in the reading tasks could, according to Zampini, be accounted for by the effect of orthography (the spirantized allophones are spelled as $<b$, $\mathrm{d}, \mathrm{g}>$ ).

Taken together, the results of the previous studies suggest that task type and the amount of attention paid to speech form may have a considerable bearing on the learner's phonetic performance. It also appears that the magnitude of the difference in performance depends on factors such as the phonological patterns of the learner's L1 (e.g. the existence of a given L2 pronunciation feature in casual L1 speech or the impact of L1 prestige pronunciation forms on L2 performance) or the phonetic complexity of the investigated pronunciation feature (e.g. single segments vs. consonant clusters). Finally, it seems worth mentioning that the effect of attention to speech form can also be approached from the perspective of contextualisation, i.e. the notion that learners may succeed in producing a given L2 sound in controlled contexts, but fail to produce the sound in real-life communication, when they are focused on meaning (Bowen, 1972).

\section{Weak forms in $\mathbf{L} 2$ pronunciation}

The present study is concerned with the impact of attention to speech form on Polish learners' realisation of English weak forms. As given in many pedagogical books, function words in English usually have two alternative pronunciations. One of them is the strong form, i.e. the stressed pronunciation of a given function word that contains a full vowel, e.g. had /hæd/, from /from/, the /ði:/. A weak form, on the other hand, can be defined as the reduced and unstressed realisation of a given function word, e.g. had /əd/, from /frəm/, the /ðə/ (Collins and Mees, 2009). More specifically, "[a]s compared with the accented realizations of [function] words (the [strong] forms), the unaccented [weak] forms of these words show reductions of the length of sounds, obscuration of vowels towards /o, I, U/ and the elision of vowels and consonants" (Cruttenden, 2008: 266). Importantly, weak forms are the more frequent realisations of function words in English. Strong forms are only used in certain circumstances, e.g. when two function words are being contrasted as in the phrase "The letter's from him, not to him" (Roach, 2010: 90). As regards L2 speakers' realisations of this pronunciation feature, Lane (2010: 73) states that 'there have been few studies of nonnative speakers' abilities to reduce function words. They suggest that while proficient learners are able to pronounce function words with shorter length than content words, they rarely use reduced vowels in function words." One of the studies referred to by Lane (2010) was conducted by Setter (2006) and is concerned with the duration of weakened, unstressed, stressed ${ }^{1}$ and tonic syllables in the English pronunciation of native Cantonese speakers. The participants were university students from Hong Kong, who were recorded while giving oral presentations

\footnotetext{
${ }^{1}$ The three terms were used by Setter (2006); the authors of the current study take 'weakened' to mean an unstressed syllable containing a reduced vowel, while 'unstressed' is interpreted by the authors as an unstressed syllable containing an unreduced vowel. It is worth mentioning here that different classification criteria are applied in the current study, i.e. lack of stress and vowel reduction are treated as independent parameters (see section 3.3.)
} 
in class. The syllables produced by the subjects were assigned to different stress categories using auditory/perceptual judgements from the author and were contrasted with native speakers' realisations. The results of the study revealed that, among other things, the Hong Kong Cantonese speakers produced over $40 \%$ of the syllables as unstressed and less than $20 \%$ as weakened, whereas the native reference group realised more syllables as weakened than unstressed (over $34 \%$ vs. over 26\%). As referred to by Lane (2010), this finding suggests that using reduced vowels in function words was more difficult for the participants than realising the words as unstressed.

\section{The study}

The primary goal of the current study was to examine the impact of attention to language form and task type on the realisation of English function words by Polish learners of English. An additional aim was to investigate whether style-induced pronunciation shifts may depend on the degree of foreign accent in a given learner's pronunciation. As opposed to English, in Polish, "[...] vowels tend to maintain their quality and they may reduce to schwa (or be devoiced or deleted) only when phonostylistically conditioned" (Dziubalska-Kołaczyk et al., 2006). Given that the L1 sound system has been found to have a considerable influence on a learner's L2 productions, it seems safe to assume that realising English function words as unstressed and reduced may prove problematic for Polish learners. Indeed, as reported by Sobkowiak (2001), one of the errors that Polish learners of English make when pronouncing function words is the lack of reduction. He explains that, "[j] ust like most content words are pronounced fully, i.e. according to the way they are spelled, so are function words pronounced as strong forms rather than weak (Sobkowiak, 2001: 293).

Interestingly, literature on reduction processes in casual speech and previous research on the effect of task type on L2 productions lead to the formation of conflicting hypotheses about the influence of attention to language form on the realisation of weak forms by learners of English. Following Tarone (1979; 1982), Polish learners can be expected to produce more weak forms when using the superordinate style (i.e. the style in which the maximum amount of attention is paid to language form), as it is the speech style most permeable to invasion from the TL. Thus, a more formal elicitation task such as reading should prompt Polish learners to use more weak forms than a less formal elicitation task such as free speech. With regard to the current study, it could be hypothesised that the greatest amount of attention will be paid to speech form when the participants are asked to read a text in English, and so the number of weak forms produced during this stage of the experiment should increase. Correspondingly, it could be hypothesised that the least amount of attention will be paid to language form when the informants are asked to deliver spontaneous speech, and so the number of weak forms should decrease during this stage of the experiment.

On the other hand, reduction processes are generally more common in less careful, casual speech (Shockey, 2003) and realising a function word as weak may be considered a reduction. Looked at from this standpoint, Polish learners could be assumed to use more weak forms in less formal elicitation tasks. Also, the results of some studies (e.g. Weinberger, 1987; Lin, 2001) have shown no significant correlation between increased 
pronunciation accuracy and increased task formality. Hence, it could be hypothesised that the greatest amount of weak forms will be produced by the participants in more informal elicitation tasks, when they are instructed to deliver prepared and spontaneous speech, and that the amount of weak forms will decrease when the subjects are required to read a text in English.

Given that entirely different predictions can be made about the effect of attention to speech form on the productions of weak forms in L2 pronunciation (the greatest amount of TL forms used either in the most formal task or in the least formal task), the issue seems an interesting and promising object of study. To recapitulate, the primary aim of the current investigation is to examine how attention to speech form influences the production of weak forms by Polish learners of English by analysing their production in different elicitation tasks.

\subsection{Data elicitation}

The study is based on the data elicited when the participants, second-year students of English Studies, were asked to perform several reading and speaking tasks as a phonetics course completion requirement. The data was elicited and tape recorded (IC Recorder ICD-UX200) in two stages. First, the students were instructed to read the Please call Stella (http://accent.gmu.edu/) text. Next, the students took part in a mock job interview, which comprised two components (each circa 3 minutes long): delivering a prepared speech where the students answered questions they were familiar with beforehand and instructed to prepare for, e.g. Why are you suitable for this kind of a job? or What do you expect from your supervisor?, and delivering a spontaneous speech where the students were asked questions they did not know prior to the recording, e.g. Do you prefer to work alone or in a team? or Do you think there are any disadvantages of being a translator/a teacher?

\subsection{Participants}

Twelve second-year students of English Studies from the University of Łódź (six females and six males) were selected out of a group of approximately 60 students on the basis of the degree of foreign accent in their pronunciation. All of the students were enrolled in a phonetics course that covered practice in suprasegmentals, focusing on sentence stress and the realisation of weak forms in particular. The students' pronunciation was auditorily rated for accentedness by the authors, who acted as teachers of pronunciation. The authors used a 5-point scale that ranged from heavilyaccented speech on the one end (1), and native-like pronunciation on the other (5). The assessment of the students' pronunciation took place during the mock job interviews described in the previous subsection. The selection of the participants was conducted in two stages. First, the students were divided into two groups: those who were judged to speak with a slight degree of foreign accent (students who received a 4 or a 5 mark on the 5-point scale) and those who were judged to speak with a relatively heavy Polish accent (students who received a 1 or a 2 mark on the 5-point scale) . Next, six 
participants with the most native-like pronunciation and six participants with the heaviest Polish accent were chosen from each group (females and males evenly).

\subsection{Data analysis}

The recordings of each participant were transcribed by the authors. As each stage of the data elicitation procedure was based on different material, a selection of weak forms that were present in all three elicitation tasks had to be made. Ultimately, the production of six function words was taken into consideration for the purpose of the current study: to, the, of, and, a, for.

The key element in data analysis was the operationalisation of 'weakness' in the forms treated as weak. Initially, it was assumed that the selected function words would be assessed as weak forms when realised with a reduced vowel / $/$. Nevertheless, it transpired that the participants repeatedly produced the chosen function words with various vowel qualities different than /ə/. At the same time, they mostly realized the function words as non-prominent, regardless of the elicitation task. Given that, a new approach was applied, i.e. a particular function word was considered a weak form if realized as a non-prominent element of an utterance (one that did not stand out amongst other elements of an utterance). Thus, unlike in Setter's (2006) study (who concentrated on both the stress/unstressed feature of English syllables as well as the reduced/unreduced vowel aspect), it was only the prominence or non-prominence of a given function word that was taken into consideration in the current investigation. Weak forms in the current study were assigned to prominent/non-prominent category by using auditory analysis, which was based on the authors expertise as pronunciation instructors and their experience with Polish-accented English and native accents of English. It is also important to note that some utterance-initial and utterance-final function words were excluded from the analysis, e.g.

1. yes I (.) because children nowadays are (.) very disobedient (.) and they do not respect teachers actually

2. so firstly I er really enjoy translating (.) and er (.) I suppose it's (.) it's important to (.) to be involved in what you are doing

3. ahm due to (.) ahm (.) feedback fro- you receive from other people (.) $\mathrm{mmm}$ (.) and (.) exchange of ideas er but on the other hand.

The abovementioned examples show some of the instances where the function word and was treated as an utterance-initial discourse marker by the authors, as it was used by the participants in order to emphasise they had not finished their thought and had something additional to say. Given that the conjunction and was realised in its strong form in such contexts, it was excluded from analysis in the current study. Additionally, as referred to by Cruttenden (2008), function words which occur utterance-finally receive stress and therefore are pronounced in their strong forms. Hence, function words used in such circumstances, e.g. the function word to in the examples above, were excluded from the analysis. 
In order to determine whether the number of weak forms used by the two groups of participants change across the three elicitation tasks, the overall percentage of the selected function words pronounced as weak forms by the two groups of subjects in three elicitation tasks was estimated. What is more, with regard to the question of whether target-like production of any of the investigated words was especially problematic for advanced Polish students of English, the percentage of weak forms in the overall number of realizations of a particular function word across three elicitation tasks in the productions of the two groups of participants, one with a relatively heavy Polish accent and the other with close to native-like pronunciation, was calculated.

\subsection{Results}

When analysed in terms of a proportion of function words realised as weak (i.e. unstressed but not necessarily produced with a reduced vowel), the results show a slight tendency for the subjects to use more weak forms in the reading task than in the prepared and free speech tasks, although the differences are rather small. Also, the vast majority of function words were realised as weak in all three tasks (Fig. 1).

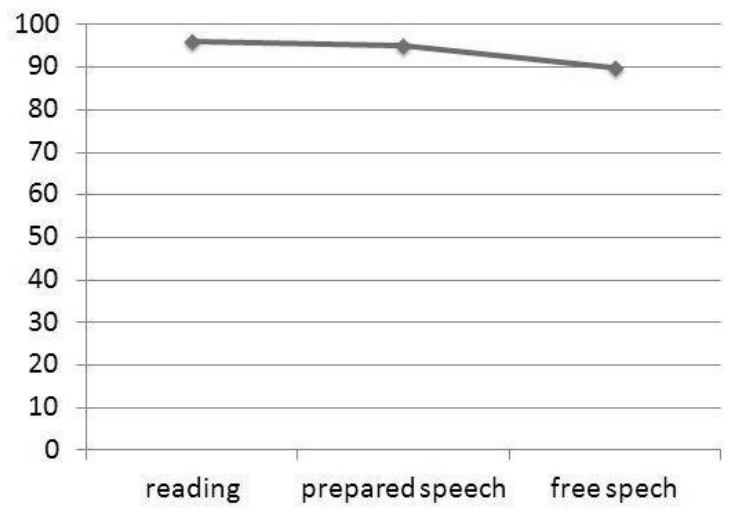

Figure 1: Percentage of function words realised as weak across three tasks (total no. of function words in: reading task $=167$, prepared speech task $=273$, free speech task=244).

A similar tendency can be observed when the proportion of function words realised as weak is analysed separately for the two groups of participants, i.e. those speaking with a relatively heavy Polish accent and those with a near native-like pronunciation (Fig. 2). It can be seen that although both groups of participants used more weak forms in the reading task than in the two remaining elicitation tasks, the difference in the number of function words realised as weak between different tasks is extremely small. Overall, the vast majority of the function words were produced as weak. The results also show that the participants with foreign-accented pronunciation realised fewer function words as weak as compared with the participants with a lower degree of foreign accent in their pronunciation. 


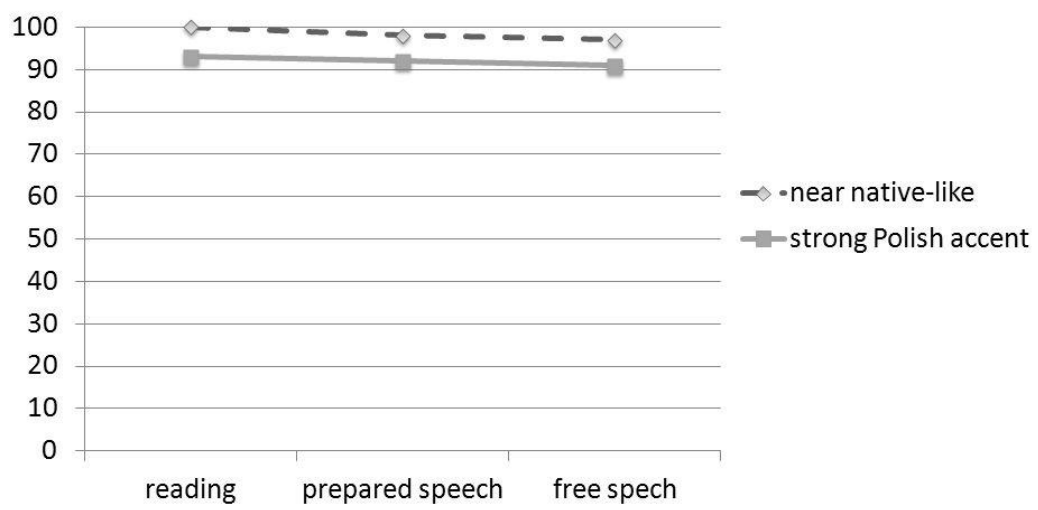

Figure 2: Percentage of function words realised as weak by the two groups of participants.

Table 1. shows the percentage of weak forms in the total number of realizations of a particular function word across three tasks in the productions of the participants with a relatively heavy Polish accent. The results show that there are no marked differences between individual function words as far the number of TL forms is concerned, although the determiner $a$ was always realised as weak, while the conjunction and is the function word with the greatest amount of strong realisations.

\begin{tabular}{|l|l|l|l|}
\hline function word & reading & prepared speech & free speech \\
\hline to & 100 & 80 & 85 \\
\hline the & 100 & 97 & 79 \\
\hline of & 83 & 100 & 90 \\
\hline and & 83 & 78 & 70 \\
\hline a & 100 & 100 & 100 \\
\hline for & 92 & 100 & 55 \\
\hline
\end{tabular}

Table 1: Percentage of weak forms in the total number of realizations of a particular function word across three tasks in the productions of the participants with foreign-accented pronunciation.

A similar tendency can be observed in the case of participants with a close to native-like pronunciation (Table 2), i.e. no substantial differences between individual function words can be observed as far the number of target-like realisations is concerned. The function words with the largest amount of weak forms are the determiner $a$ and the, while the function word with the greatest amount of strong realisations is the conjunction and.

\begin{tabular}{|l|l|l|l|}
\hline function word & reading & prepared speech & free speech \\
\hline to & 100 & 100 & 98 \\
\hline the & 100 & 100 & 100 \\
\hline of & 100 & 100 & 95 \\
\hline and & 100 & 88 & 91 \\
\hline$a$ & 100 & 100 & 100 \\
\hline
\end{tabular}




\begin{tabular}{|l|l|l|l|}
\hline function word & reading & prepared speech & free speech \\
\hline for & 100 & 100 & 94 \\
\hline
\end{tabular}

Table 2: Percentage of weak forms in the total number of realizations of a particular function word across three tasks in the productions of the participants with near native-like pronunciation.

\section{Discussion}

The results of the study show that, overall, more TL forms were produced by the participants in the most formal elicitation task. It appears that the more attention the participants paid to language form, the greater number of weak forms was used. The finding lends some support to Tarone's claims $(1979 ; 1982)$ about the impact of attention and task type on learners' phonetic performance and runs counter to the assumption that a relatively informal task would elicit more reduced productions. Nonetheless, the participants produced the investigated function words as weak in the majority of cases and so the effect of task type appears to be rather small. The fact that the subjects produced slightly more TL forms when reading the Please call Stella text may also be due to the fact that the task took place soon after discussing and practicing weak forms in the phonetics course. As a result, the subjects were probably mindful of weak forms and this aspect of English pronunciation may have figured relatively high in their consciousness at that particular point in time. Furthermore, the participants were already quite familiar with the Please call Stella text before the recordings for the current study took place, which could also facilitate target-like productions. Finally, all of the participants could be considered to be advanced learners of English and hence it is possible that producing English function words as unstressed no longer causes great difficulties for them.

As far as the amount of foreign-accentedness in a particular learner's productions is concerned, the results of the study revealed no marked differences between the group of participants who spoke with a relatively heavy Polish accent and the group of participants who used close to native-like pronunciation. The finding indicates that, with respect to the degree of prominence (but not necessarily with respect to vowel reduction), realising function words as unstressed is relatively easy for advanced Polish learners of English. It also suggests that, in this particular case, the effect of task type on L2 phonetic performance is weakly or not at all related to the degree of foreign accent in a given learner's pronunciation.

Although the primary goal of the current study was to examine the effect of task type and attention to language form on L2 pronunciation, some far more interesting questions arose in the course of the investigation. Namely, how exactly should one define 'weakness' in a weak form and what should be the teaching aims as regards the pronunciation of English function words? If one looks at weak forms only from the point of view of their 'non-prominence', the results of the current study illustrate that this particular feature of English pronunciation is not especially difficult for advanced Polish learners (the analysed function words were predominantly realised as unstressed), which could mean that weak forms do not need to receive high priority in pronunciation 
teaching. Indeed, Jenkins (an advocate of looking at English as an international rather than foreign language), once stated that

[...] learners can safely abandon weak forms (the production of words like 'to' and 'from' as /to/ and /from/ in fast speech) [...] I would argue that it is possible to highlight some syllables without necessarily reducing others, and that some native varieties do precisely this, along with the vast majority of fluent bilingual speakers. Lack of weak forms may prove disconcerting for some native receivers, but is unlikely to do so for non-natives (Jenkins, 1998: 123).

Thus, if one defines 'weakness' in English function words solely as the lack of prominence (not coupled with vowel reduction), aims in English pronunciation teaching could be redefined so that little or no emphasis is placed on the production of weak forms. The results of the current study suggest that learners pick up on the 'unaccentedness' of weak forms fairly quickly (and possibly without direct instruction to do so). Additionally, as argued by Jenkins (ibid.), obscuration of vowel quality could reduce the intelligibility of a given learner's pronunciation to other non-native speakers of English.

On the other hand, if one was to define 'weakness' in English function words as a lack of prominence coupled with vowel reduction, it seems that considerable importance should be given to weak forms in English pronunciation teaching. Although vowel quality as such was not the object of study in this particular investigation, the authors' impression is that the participants exhibited considerable variability as far as this phonetic feature is concerned. The observation accords with Lane's (2010: 73) statement that "proficient learners [...] rarely use reduced vowels in function words." Hence, one could argue that weak forms should be given high priority in English pronunciation teaching. The 'weakening 'of English function words (seen as the obscuration of vowel quality and lack of stress) can be viewed as a crucial element of English pronunciation also if one is more inclined to treat English as a foreign language and assumes that its learners aspire to be intelligible to native speakers. As stated by Roach (2010: 88), “[...] most native speakers of English find an "all-strong form" pronunciation unnatural and foreign-sounding." In addition, "[...] speakers who are not familiar with the use of weak forms are likely to have difficulty understanding speakers who do use weak forms [...] (Roach, 2010: 88)."

At this point, another interesting question arises. If one is interested in the vowel quality of weak forms in non-native speech (and not focuses solely on the prominent/non-prominent distinction), how is one to decide what vowel quality is to be considered as reduced and what combination of spectral characteristics should be treated as a full vowel? Given the high variability of reduced vowel qualities, using acoustic measures and spectral analysis seems to be a rather complex and essentially arbitrary solution to the problem. Perhaps it would be possible to determine whether a given realisation should be treated as reduced by asking a separate group of listeners (native and non-native?) for perceptual judgements. With a sufficiently numerous and diverse group of listeners, such a method could allow one to objectively determine whether the learners' are producing reduced vowels in weak forms or not. It could also shed some light on which acoustic characteristics are necessary for a vowel to be perceived as reduced in a given phonetic context. 
Interestingly, when analysing the elicited data, the authors of the study observed that it was not only the vowel quality in weak forms that was realised with considerable variability by the participants. In fact, vowels in the strong forms of function words were also realised differently by the participants and their productions often deviated from the TL forms. If one's goal in English pronunciation teaching is for the learners to sound native-like, it seems that vowel quality in strong forms of function words should also receive closer attention.

\section{Conclusions}

The results of the study indicate that although increased attention to language form seems to have caused the participants to realise more function words as unstressed, the effect was very small and may be interrelated with the fact that the investigated pronunciation feature was placed relatively high in the learners' consciousness. Overall, the „unaccented" aspect of English weak forms appears to cause little difficulties for advanced Polish learners of English. What seems worth exploring further is the vowel quality of English function words (both weak and strong forms) as used by Polish learners. The results of the study also suggest that, in this particular case, the effect of attention to language form is weakly or not at all related to the degree of foreign accent measured with the use of accentedness ratings provided by the authors of the study) in a speaker's L2 pronunciation.

\section{References}

Beebe, L. (1980) Sociolinguistic variation and style shifting in second language acquisition. Language Learning 30, 433-447.

Bowen, D. J. (1972) Contextualizing pronunciation teaching in the ESOL classroom. TESOL 5, 83-97.

Cruttended, A. (2008) Gimson's pronunciation of English. London: Hodder Education.

Dickerson, L. and Dickerson, W. (1977) Interlanguage phonology: current research and future directions. In S. P. Corder and E. Roulet (eds). The Notions of Simplification. Interlanguages and Pidgins: Actes du Seme Colloque de Linguistique Applique de Neufchatel, 18-30.

Dziubalska-Kołaczyk, K., Bogacka (Balas), A, Pietrala, D., Wypych, M. and Krynicki, G. (2006) PELT: An English language tutorial system for Polish speakers, MultiLing, Volume ISCA Tutorial and Research Workshop on Multilingual Speech and Language Processing, Stellenbosch, South Africa, p.on CD.

Collins, B. and Mees, I. M. (2009) Practical phonetics and phonology. A resource book for students. New York: Routledge.

Gatbonton, E. (1975) Systematic variations in second language speech: a sociolinguistic study. PhD Dissertation, McGill University.

Jenkins, J. (1998) Which pronunciation norms and models for English as an International Language? ELT Journal, 52/2:119-126. 
Labov, W. (1969) The study of language in its social context. Studium Generale 23, 30-87.

Lane, L. (2010) Tips for Teaching Pronunciation: A Practical Approach. Harlow: Pearson Longman.

Lin, Y. (2001) Syllable simplification strategies: a stylist perspective. Language Learning 51, 681-718.

Roach, P. (2010) English Phonetics and Phonology. A practical course. Cambridge: Cambridge University Press.

Schmidt, R. (1987) Sociolinguistic variation and language transfer in phonology. In G. Ioup and S. H. Weinberger (eds), Interlanguage phonology: The acquisition of a second language sound system. Rowley, MA: Newbury House.

Shockey, L. (2003) Sound Patterns of Spoken English. Oxford: Blackwell Publishing.

Setter, J. (2006) Speech rhythm in World Englishes. The Case of Hong Kong. TESOL Quarterly 40, 763-782.

Sobkowiak, W. (2001) English Phonetics for Poles. Wydawnictwo Poznańskie.

Weinberger (eds), Interlanguage phonology: The acquisition of a second language sound system. New York: Newbury House, 365-377.

Tarone, E. (1979) Interlanguage as chameleon. Language Learning 29, 181-191.

Tarone, E. (1982) Systematicity and attention in interlanguage. Language Learning 32, 69-84.

Weinberger, S. H. (1987) The influence of linguistic context on syllable structure simplification. In G. Ioup and S. H. Weinberger (eds), Interlanguage phonology: The acquisition of a second language sound system. Rowley, MA: Newbury House, 401-417.

Zampini (1994) The Role of Native Language Transfer and Task Formality in the Acquisition of Spanish Spirantization. Hispania 77, 470-481. 